\title{
Discussion on Fire Characteristics of Dwellings with a Small Courtyard
}

\author{
WEIYUN WANG \\ Sichuan Fire Research Institute \\ PRC
}

ABSTRACT

In order to probe the function of the small courtyard during fire, studies and fire tests in a real dwelling building and an analog building with a small courtyard have been carried out in China. The preliminary conclusions are:

1. The small courtyard in dwelling building can play a valuable part in ventilating smoke and heat. When the building is on fire, the small courtyard will be helpful to evacuating residents and extinguishing fire by fire-fighters.

2. The horizontal distance between any two windows in the courtyara should not be less than 3.3 meters.

The paper provides theoretically the detailed analysis of the above conclusions and test data in many aspects. These data have been provided as a valuable reference for the code of Fire-Prevention in Building Design.

KEYWORDS

Small courtyard, Fire characteristics, Smoke ventilation, Heat ventilation, Resident evacuation, Chimney effect, Cooling, Thermal radiation, Heat conduction, Heat convection.

Because of the rapid development of the building industry in China, the land for buildings is in short supply day by day. Therefore, dwelling buildings with a small courtyard and a long distance from entrance to the rear, which could reduce the occupied area of land for building, have been developed since 1970's. As the main purpose of the small courtyard in this kind of buildings is to obtain light and ventilation, windows are designed in the courtyard walls in accordance with the necessary functions. In some cases there are windows in two sides of the courtyard walls. In the other cases there are windows in three even four sides of the courtyard walls (Figure 1). Among the departments concerned, there arouse the arguments about what would be the advantages and disadvantages of the courtyard under fire. And this problem often occurs especially in the examination of architectural design in fire prevention. 


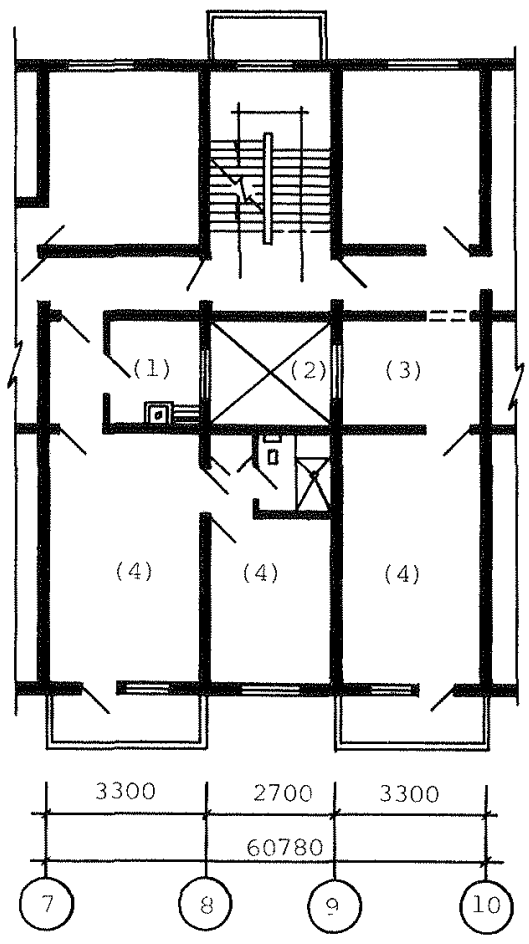
(1) Kitchen
(2) small courtyard
(3) living room
(4) bedroom

\author{
Figure 1. The six-storey \\ dwelling building with a \\ small courtyard of a \\ factory in Beijing
}

In order to solve the problem theoretically, The Fire Bureau of The Ministry of Public Security ordered The Sichuan Fire Research Institute to study the fire characteristics of this kind of buildings. To make the research deeper and more extensive, the institute has invited professors, senior engineers, engineers and technicians from 12 units, which are some concerned universities, design institutes, research institutes, factories, fire brigades and some units in charge of construction, to participate in the research.

During the three years' research, the fire tests in a real six-storey building and in an analog building with a certain proportion have been obserred and measured in many aspects. The various phenomena and the test data on the testing ground have been recorded in detail, such as temperature, intensity of thermal radiation, intensity of illumination, concentration of smoke particles, chemical compositions of smoke, airflow pressure in the courtyard, airflow velocity and partial climate on the testing ground. Through repeated tests and studies, the following conclusions have been derived.

1. The small courtyard in dwelling buildings can play a valuable part in ventilating smoke and heat. It will be helpful to evacuating residents under fire and extinguishing fire by fire-fighters.

2. If the courtyard walls are made of noncombustible materials, the size of windows is $1480 \times 980(\mathrm{~mm})$, the shortest safe distance between any 
two windows in the courtyard walls should not be less than 3.3 meters.

Why could the small courtyard play a valuable part in ventilating smoke and heat?

It is well known that once a room, which is closest to the courtyard, catches fire, the glass in the windows of that room will be broken or damaged. Then the smoke and flame in the room will spread into the courtyard by heat-pressure. Therefore the courtyard is rapidly heated and there will be a pressure difference between the upper and lower sides of the courtyard. It is called "Chimney Effect". With this effect, not only the heat and the smoke in the building could spread out directly into the sky, but also the airflow with normal temperature in the rooms on the other floors, in which there are windows connecting to the courtyard, would spread into the sky through the courtyard. When the airflow with normal temperature flows rapidly into the courtyard, it could continuously cool the respective window opening and virtually protect the window itself. At the same time it also continuously reduces the temperature of the hot airflow in the courtyard. Under this organization of the airflows, the smoke and the hot airflow in the burning room can only spread directly into the sky through the courtyard, but not into the windows of the rooms all round the courtyard (Figure 2).

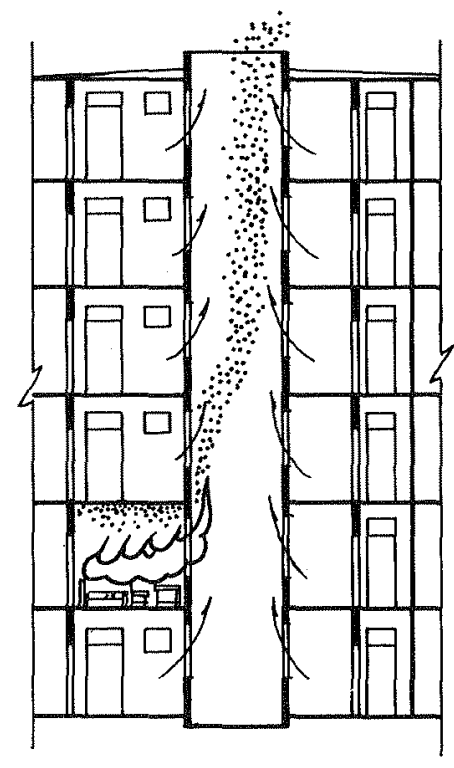

Figure 2. Show of the flowing smoke and cool aixflow in the courtyard

$\longrightarrow$ : cool airflow

If:in: smoke and hot airflow

Tests have proved that the stronger the fire is, the faster the speed of the smoke and the hot airflow into the sky, then the more the cool airflow from no-fire rooms into the courtyard. So, it is more difficult for the smoke and the hot airflow to rush into the no-fixe rooms. This has been proved by all the results of tests and measures of airflows. When the temperature on all test points arrives its highest degree, just then, the speed of the airflow in the courtyard is the fastest. For example, 
there is test data during the 4th test in Table 1, as follows:

Table 1. Comparison of Temperature and Airflow speed in the Courtyard

\begin{tabular}{llllllll}
\hline $\mathrm{T}(\mathrm{min})$ & 0 & 5 & 10 & 15 & 20 & 25 & 30 \\
\hline $\mathrm{t}\left({ }^{\circ} \mathrm{C}\right)$ & 18 & 120 & 200 & 130 & 96 & 64 & 60 \\
\hline $\mathrm{V}(\mathrm{m} / \mathrm{s})$ & 1.239 & 2.036 & 3.195 & 2.062 & 1.973 & 1.333 & 1.325 \\
\hline
\end{tabular}

It was derived that the faster the speed of the airflow is, the more the heat is carried away, and the function of ventilating smoke and heat of the small courtyard is clearer.

Due to the good ventilating effect of smoke and heat of the small courtyard, there is good visibility and no smoke invasion in public exits, such as the corridor, staircases, etc. Out of the burning room. Meanwhile, the contents of various gases can't make up the danger for evacuating people. Therefore, the evacuation of the residents, lifesaving and fire extinguishing works are easiex now. (see our test records, Table 2)

Table 2. The Table of Chemical Composition of Smoke (Records in Nov. 1979)

\begin{tabular}{|c|c|c|c|c|c|}
\hline \multirow{2}{*}{$\begin{array}{l}\text { Chemical } \\
\text { Composition }\end{array}$} & \multirow{2}{*}{$\begin{array}{c}\text { Place } \\
\text { Measured }\end{array}$} & \multicolumn{3}{|c|}{ Number } & \multirow[b]{2}{*}{4} \\
\hline & & 1 & 2 & 3 & \\
\hline \multirow{2}{*}{$\begin{array}{c}\mathrm{O}_{2} \% \\
\text { the lowest } \\
\text { content }\end{array}$} & $\begin{array}{l}\text { Kitchen on the } \\
\text { second floor }\end{array}$ & 19.2 & 18.5 & 17.9 & 17.7 \\
\hline & $\begin{array}{l}\text { Corridor on the } \\
\text { second floor }\end{array}$ & 12.6 & 14 & 19.7 & 19.9 \\
\hline \multirow{2}{*}{$\begin{array}{l}\text { co } \\
\text { the highest } \\
\text { content }\end{array}$} & $\begin{array}{l}\text { Kitchen on the } \\
\text { second floor }\end{array}$ & $\begin{array}{l}\text { too low } \\
\text { to be } \\
\text { measurea }\end{array}$ & $\begin{array}{l}\text { too low } \\
\text { to be } \\
\text { measured }\end{array}$ & 0.003 & 0.006 \\
\hline & $\begin{array}{l}\text { Corridor on the } \\
\text { second floor }\end{array}$ & 0.0052 & $\begin{array}{l}\text { too low } \\
\text { to be } \\
\text { measured }\end{array}$ & 0.035 & 0.0032 \\
\hline \multirow{2}{*}{$\begin{array}{c}\mathrm{CO}_{2} \% \\
\text { the highest } \\
\text { content }\end{array}$} & $\begin{array}{l}\text { Kitchen on the } \\
\text { second floor }\end{array}$ & 0.13 & 0.04 & 0.05 & 0.1 \\
\hline & $\begin{array}{l}\text { Corridor on the } \\
\text { second floor }\end{array}$ & 0.11 & 0.04 & 0.25 & 0.09 \\
\hline \multirow{2}{*}{$\begin{array}{l}\mathrm{NO}_{\mathrm{X}} \mathrm{mg} / \mathrm{M}^{3} \\
\text { the highest } \\
\text { content }\end{array}$} & $\begin{array}{l}\text { Kitchen on the } \\
\text { second floor }\end{array}$ & 2 & $\begin{array}{l}\text { too low } \\
\text { to be } \\
\text { measured }\end{array}$ & 2 & 10 \\
\hline & $\begin{array}{l}\text { Corridor on the } \\
\text { second floor }\end{array}$ & 2 & $\begin{array}{l}\text { too low } \\
\text { to be } \\
\text { measured }\end{array}$ & 20 & 1 \\
\hline $\mathrm{SO}_{2} \%$ & $\begin{array}{l}\text { Kitchen on the } \\
\text { second floor }\end{array}$ & 0.1 & 0.26 & 0.26 & 0.99 \\
\hline $\begin{array}{l}\text { the highest } \\
\text { content }\end{array}$ & $\begin{array}{l}\text { Corridor on the } \\
\text { second floor }\end{array}$ & $\begin{array}{l}\text { too low } \\
\text { to be } \\
\text { measured }\end{array}$ & $\begin{array}{l}\text { too low } \\
\text { to be } \\
\text { measured }\end{array}$ & $\begin{array}{l}\text { too low } \\
\text { to be } \\
\text { measured }\end{array}$ & $\begin{array}{l}\text { too low } \\
\text { to be } \\
\text { measured }\end{array}$ \\
\hline
\end{tabular}

On the safe section size of the small courtyard, the fire tests have 
proved: the shortest horizontal distance between any two openings around the courtyard should not be less than 3.3 meters. If the distance is less than $3.3 \mathrm{M}$, the flame spurted from a window at one side of the courtyard may easily cross the courtyard and burn the combustible materials at the opposite window, such as hanging curtains or wood window frames, causing fire to spread continually from the window to the inside of the room. (see Table 3).

Table 3. Five Test Results on Different Distances between the Two windows in the courtyard

\begin{tabular}{lllll}
\hline Distance between windows $(\mathrm{m})$ & 2.7 & 3.0 & 3.3 \\
\hline $\begin{array}{l}\text { The opening of the } \\
\text { Window in the } \\
\text { kitchen room }\end{array}$ & $\begin{array}{l}\text { The highest } \\
\text { temperature }\left({ }^{\circ} \mathrm{C}\right)\end{array}$ & 502 & 310 & 160 \\
\hline $\begin{array}{l}\text { The curtain hanging } \\
\text { over the window }\end{array}$ & burnt & flaming no damage \\
\hline
\end{tabular}

There is a problem, which needs to be explained further. As the high-speed airflow has already taken away a lot of heat in the courtyard into the sky, and the cool airflow from no-fire rooms into the courtyard plays a valuable part in protecting windows of the rooms itself, why could the window opening opposite to the burning room be in the danger of burning if the horizontal distance between two windows is less than 3.3 M? It should be analyzed with the basic principles of heat transmission.

There are three primary ways of heat transmission: heat conduction, heat convection and heat radiation.

\section{Heat conduction}

In the case of fire, there is a space between the heat source and the bodies to be heated. Here the space is the courtyard, the heat source is the burning room and the bodies to be heated are the combustible materials at the window opening opposite to the burning room, such as curtains and wood frames, and so on. If the heat produced by fire is transmitted to the opposite window opening by conduction, it must be accomplished by the two sides of the courtyard walls around the burning room. But because the coefficient of heat conduction of a brick wall is very small (about $0.37 \mathrm{Kcal} / \mathrm{m} \cdot \mathrm{h} .{ }^{\circ} \mathrm{C}$ ), it will need too much time to conduct heat. According to the test results about fire resistant limits of structural components in china, for a red brick wall, only $240 \mathrm{~mm}$ thick, it takes 11.5 hours to make the temperature at the back of the surface against fire to reach $220^{\circ} \mathrm{C}$ under the standard fire temperature. Thus, it would take too much time to conduct heat through the brick wall along the corner which is 4 meters long. As for the fire, which occured in the room close to the courtyard, it takes only 10 minutes to reach the highest fire temperature $1130^{\circ} \mathrm{C}$ from the growing period to the flourishing period. After that the fire temperature would reduce gradually. Therefore, it is too difficult to conduct the heat to the window opening at the opposite side of the courtyard through the brick walls in such a short fixe time. In other words, rather more precisely, heat conduction could be neglected in the analysis.

\section{Heat convection}

When the flame spurts from the window of the burning room into the courtyard, it heats intensively heat transmitting medium, the air. Because of the strong spurt of the flame, the hot airflow lashes the opposite window opening or the wall. But as the higher the temperature of the 
airflow is, the more intensive the extractive force of the courtyard. In addition, the cool airflow from the opposite window opening flows into the courtyard, protecting the opposite window itself. So most of the hot airflow would be exhausted rapidiy and could not make the combustible materials at the opposite window opening to get much heat. In other words, the effect of heat exchange between these two opposite windows by heat convection is small too.

\section{Heat radiation}

This kind of heat transmission is different from the above two, which could transmit heat only with heat transmitting medium. Without any medium, it could radiate heat directly to the body to be heated in form of electromagnetic waves with wavelengths between $0.4 \mu$ to $40 \mu(1 \mu=$ $\left.10^{-6} \mathrm{M}\right)$. Generally, it is not disturbed by aixflows during transmitting heat. So the heat absorbed by combustible materials, such as curtains or wood frames of the window opening opposite to the burning room, is mainly heat of radiation.

But, why couldn't curtains or wood frames burn in spite of such an intensive heat radiative source, $i . e .$, the burning room, and such a short distance, i.e., 3.3 meters?

This is because there is a heavy loss in heat radiation. As we know, so long as the temperature of a body is higher than absolute zero, a body not only absorbs the radiative heat around it, but also radiates heat out. so the bodies, such as curtains or wood frames, do the same. When they absorb the radiative heat, part of the heat is absorbed by themselves, the others are reflected into the smoke and the airflow, which continuously flow up into the courtyard. As indicated before, generally, air couldn't resist the heat radiation. But, there are a lot of gases with three or more atoms in the smoke under fire, such as $\mathrm{H}_{2} \mathrm{O}, \mathrm{CO}_{2}, \mathrm{CH}_{4}, \mathrm{NH}_{3}, e t c$. These gases with three atoms could absorb the radiative energy. so part of heat under fire would be taken away by these gases, which are continuously going upwards. In addition, because heat would be transmitted to colder bodies by mediums, the radiative heat, absorbed by curtains or window frames, would be transmitted to their back surfaces through themselves, and continually transmitted from the back surfaces to other bodies in the room. At the meantime, the cool airflow, which flows from the room into the courtyard, continuously takes away the heat from the back surface of the combustible materials. Some heat, absorbed by the surface opposite to fire is together with the cool airflow, entering the courtyard and being exhausted to the sky. This means that during fire the combustible bodies, such as curtains and wood window frames, continuously absorb the radiative heat and loss it simultaneously. This is the main reason why curtains and window frames could not burn in spite of such an intensive radiative heat source and such a short distance (3.3M).

Otherwise, if there is no airflow circulation in the courtyard, which is joined by the cool airflow from no-fixe rooms, inevitably the window opening opposite to the burning room would burn under the same condition. This has been proved by fire records of many countries over the world. It was not rare that during fire a house made of wood board burned down by the radiative heat, which was tens or even onehundred meters away from it. This also proves that the small courtyard operates a special function for exhausting smoke and heat. 
REFERENCE

1. The Pedagogic Research Group on Metallurgical Furnace of the Anshan Institute of Iron and Steel, "Metallurgical Furnace and Its Fuel", Apri1, 1963. 
